\title{
Prospecção arqueológica em áreas de floresta - contribuição metodológica da pesquisa na área do Projeto Salobo (Pará)
}

\author{
Maura Imazio da Silveira* \\ Maria Christina Leal Rodrigues** \\ Christiane Lopes Machado*** \\ Elisangela Regina de Oliveira *** \\ Louis-Martin Losier**
}

\begin{abstract}
SILVEIRA, M.I.; RODRIGUES, M.C.L.; MACHADO, C.L.; OLIVEIRA, E.R.; LOSIER, L.-M. Prospecção arqueológica em áreas de floresta - contribuição metodológica da pesquisa na área do Projeto Salobo (Pará). Revista do Museu de Arqueologia e Etnologia, São Paulo, 19: 155-178, 2009.
\end{abstract}

Resumo: O projeto de Prospeç̧ão arqueológica na área do Projeto Salobo - PA foi desenvolvido entre 2003 e 2006 pelo Museu Paraense Emílio Goeldi com a finalidade de identificar e avaliar os impactos da implantação de atividades mineradoras da empresa VALE ao patrimônio arqueológico, além de indicar medidas necessárias para sua preservação ou resgate. $\mathrm{O}$ presente artigo tem por objetivo apresentar a metodologia de levantamento arqueológico utilizada para a identificação de vestígios arqueológicos na área da Floresta Nacional Tapirapé Aquiri (FLONATA), município de Marabá / PA, a qual será afetada pela implantação deste empreendimento. Esta experiência deverá suscitar discussões quanto aos alcances e limites da abordagem apresentada, cujo resultado foi a identificação de 22 sítios e cinco ocorrências arqueológicas.

Palavras-chave: Prospecção arqueológica - Floresta Amazônica - Sudeste do Pará - Salobo - Metodologia de levantamento arqueológico.

\section{Introdução}

Projeto Salobo é um empreendimento da Salobo Metais S/A (SMSA) -
VALE cujo objetivo é promover a lavra e beneficiamento da jazida polimetálica do igarapé Salobo visando ao seu aproveitamento econômico. Em junho de 2002 o Museu Paraense Emílio Goeldi (MPEG/MCT) elaborou o Diagnóstico arqueológico da área do

$\left.{ }^{*}\right)$ Museu Paraense Emílio Goeldi - Coordenação de Ciências Humanas. <maura@marajoara.com> $\left.{ }^{* *}\right)$ Pesquisador(a) autônomo(a).<chrislealfr@hotmail.com> $<$ lmartinl@hotmail.com>

$\left({ }^{* *}\right)$ Rhea Estudos e Projetos.

<arqueologia@rheambiente.com.br>
${ }^{(* * *)}$ Museu Paraense Emílio Goeldi - Coordenação de Ciências Humanas. Pesquisadora visitante. <elisoliveira@yahoo.com.br> 
Prospecção arqueológica em áreas de floresta - contribuição metodológica da pesquisa na área do Projeto Salobo (Pará). Revista do Museu de Arqueologia e Etnologia, São Paulo, 19: 155-178, 2009.

Projeto Salobo (Silveira \& Lopes 2002) e posteriormente o Projeto de prospecção arqueológica (Silveira \& Machado 2002) atendendo à legislação ambiental e de proteção ao patrimônio arqueológico (Lei no 3964 de 1961 e Portaria nº 230 de 2000), assim como a condicionante emitida pelo Instituto Brasileiro do Meio Ambiente e dos Recursos Naturais Renováveis (IBAMA) para o licenciamento do empreendimento em questão (EIA - resolução CONAMA 001/86).

Para desenvolvimento do projeto Prospecção arqueológica na área do Projeto Salobo foi firmado em 2002 convênio entre a Salobo Metais S/A, o Museu Paraense Emílio Goeldi e a Fundação Instituto para o Desenvolvimento da Amazônia (FIDESA), cabendo à Salobo Metais o financiamento dos trabalhos, ao Museu Goeldi a realização das pesquisas e à FIDESA a gestão dos recursos.

Os trabalhos de prospecção arqueológica, coordenados pelas pesquisadoras Dra. Maura Imazio da Silveira e Profa. Christiane Lopes Machado entre os anos 2003 e 2006, cobriram todas as áreas a serem diretamente afetadas pela implantação do empreendimento. Os resultados foram apresentados em seis relatórios de pesquisa encaminhados à 2a Superintendência do Instituto do Patrimônio Histórico e Artístico Nacional - IPHAN (Silveira et al. 2003a, 2003b, 2004, 2005a, 2005b, 2006).

A pesquisa teve como principais objetivos a realização de prospecção para identificação de sítios arqueológicos, avaliação do estado de preservação destes, fornecer uma estimativa prévia da extensão, profundidade e caracterização primária dos vestígios associados, avaliar os impactos que serão causados ao patrimônio arqueológico pela implantação do empreendimento e assim propor a preservação ou o resgate dos sítios encontrados.

Este artigo apresenta a metodologia de campo empregada na prospecção arqueológica realizada na área do Salobo com o objetivo de detalhar os procedimentos adotados a fim de demonstrar não apenas a viabilidade como também discutir o alcance e limitações de levantamentos sistemáticos em áreas com densa cobertura vegetal, como as de floresta tropical.

\section{Contexto ambiental}

A área da pesquisa situa-se entre as coordenadas UTM 22M 534.000 - 564.000 Leste e 9.350.000 - 9.370.000 Norte. Está inserida na Floresta Nacional do Tapirapé-Aquiri (FLONATA), no município de Marabá, sudeste do estado do Pará, aproximadamente $600 \mathrm{~km}$ ao sul da capital Belém e integra, por extensão, a chamada "região de Carajás" (Fig. 1).

A “região de Carajás” abrange área de aproximadamente $80.000 \mathrm{~km}^{2}$ no sudeste do Pará, apresentando cobertura florestal $48 \%$ composta de floresta densa e $13 \%$ de floresta aberta. Localizada no extremo oriente desta macro-região, a jazida do Salobo está situada na margem esquerda do rio Itacaiúnas, especificamente na área banhada pela micro-bacia de seu afluente igarapé Salobo (Silva \& Rosa 1989).

O clima na região de Carajás é tipicamente tropical, quente e úmido, enquadrando-se na classificação de Köppen como tipo AW. As variações termais estão entre $24,3^{\circ} \mathrm{C}$ e $28,3^{\circ} \mathrm{C}$, sendo que nos platôs o clima é do tipo serrano com médias anuais entre $21^{\circ} \mathrm{C}$ e $23^{\circ} \mathrm{C}$ (Ab'Saber, apud Silva 1989: 34). A umidade relativa do ar é superior a 80\% (Silva 1992: 81), verificando-se duas estações bem distintas: uma seca, de julho a setembro, quando os rios baixam expondo extensas várzeas utilizadas para cultivo pela população ribeirinha que habita a região atualmente, e outra chuvosa, de dezembro a março, quando o nível das águas dos rios eleva-se permitindo a navegação por pequenas embarcações em alguns trechos.

A hidrografia é caracterizada por fortes declives e pelo regime torrencial em função do período das chuvas (CVRD 1981: 25). A maior parte da região é drenada pela rede hidrográfica do rio Itacaiúnas, afluente da margem esquerda do rio Tocantins, e seu principal tributário o rio Parauapebas (CVRD 1981: 25).

A principal cobertura vegetal é do tipo Floresta Tropical Pluvial com variações locais, a maioria obedecendo ao relevo acidentado (Salomão et al. 1988). De acordo com Silva (1992) a vegetação de Carajás pode ser dividida em dois grandes grupos: o de Floresta Tropical Pluvial - onde estão localizados os sítios 


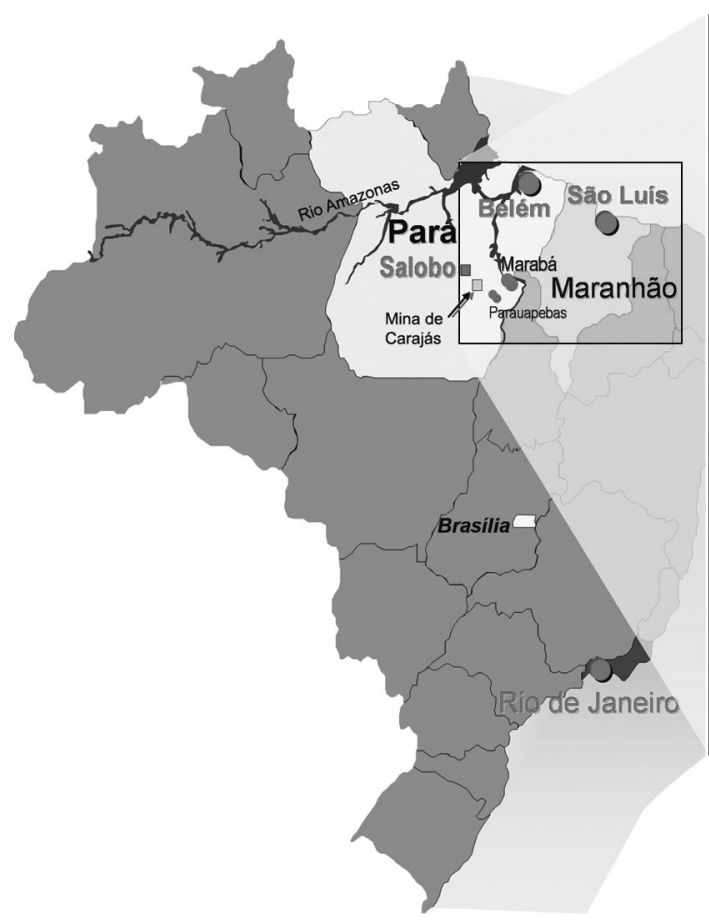

arqueológicos aqui apresentados - e a vegetação Metalófila ou Campo Rupestre, também chamada Vegetação de Canga, encontrada no topo dos platôs e nas encostas, onde estão algumas das grutas com vestígios de ocupação humana mais antiga, relacionada principalmente ao período pré-cerâmico (Silveira 1994; Magalhães 1995b, 2005).

$\mathrm{Na}$ área da pesquisa a hidrografia inclui a bacia do igarapé Salobo, delimitada a norte pelas micro-bacias dos igarapés Mirim e Mano, seus principais afluentes, e a sul pela barra do rio Cinzento com o rio Itacaiúnas (BRANDT 1998).

No levantamento pedológico foram identificadas duas classes de solo: Latossolos e Podzólicos. Segundo suas características, os solos podem ser considerados como argiloarenoso com tendência a arenoso, bem drenado. Nos trechos de aluvião apresentam-se um pouco mais úmidos e argilosos, enquanto nas encostas surgem afloramentos rochosos esparsos (notadamente de quartzito) e os solos são nitidamente mais secos (BRANDT 1998, 2002a). A cobertura pela serrapilheira ocorre em algumas áreas, com espessura que varia de 2 a 5 centímetros.

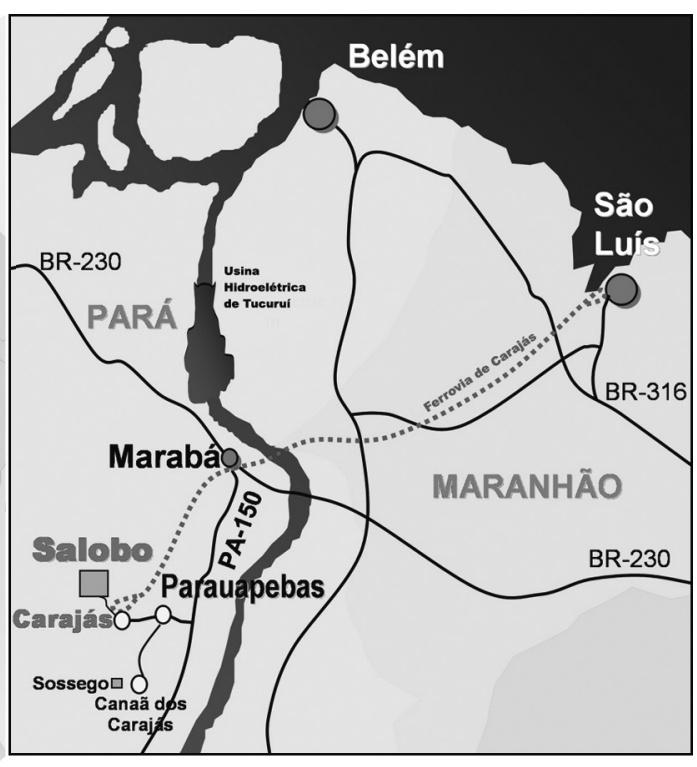

Fig. 1. Localização da área de pesquisa.

Na FLONA Tapirapé-Aquiri a formação florestal encontrada é uma variação da Floresta Ombrófila Densa, classificada como aberta por apresentar espécies vegetais que se adaptam mais às condições de luminosidade, como arbustos e lianas. As várias formas desta floresta são bastante similares em composição, densidade e tamanho das árvores, sendo diferenciada pela presença ou ausência de lianas e palmeiras (BRANDT 2002b).

O levantamento florestal realizado por BRANDT (2002b) demonstrou a predominância de árvores com altura de $10 \mathrm{~m}$ a $16 \mathrm{~m}$, com destaque para a Castanheira, o Breu Preto e o Tento. Na FLONATA a presença de Castanhais é de grande importância, tanto econômica como na constituição da vegetação, apresentando aproximadamente cinco indivíduos por hectare (BRANDT 1998).

Algumas espécies vegetais registradas na área do Projeto Salobo (Andiroba, Canela, Castanheira, Copaíba, Mucuracaá, Murta, Mutamba e Ucuuba) são utilizadas atualmente na construção de embarcações, mobiliário, moradias, além de uso alimentar, medicinal, aromático e ornamental (BRANDT 2002b; 
Silveira, Rodrigues et al. 2008). Muitas destas espécies provavelmente foram utilizadas pelas populações pretéritas que ali viveram, contudo esta caracterização não objetiva traçar um paralelo com o ambiente pré-histórico, apenas explicitar a variabilidade aí presente.

$\mathrm{O}$ zoneamento ambiental identificou quatro sub-tipos de Floresta Equatorial Ombrófila (FEO) aberta: 1) De transição sub-montanha / montanha nos platôs; 2) Sub-montanha em encostas íngremes, com palmeiras e cipós; 3) Sub-montanha em relevo colinoso, com palmeiras e cipós; 4) Terras baixas e aluviões com cipós e palmeiras (BRANDT 1998).

Observando-se a implantação dos sítios arqueológicos na paisagem verificou-se que a maior parte deles encontra-se próxima a fontes de água (igarapés e nascentes), pedrais, pontos estratégicos em área plana e, geralmente, livre de inundação. Estão situados nas terras baixas e aluviões com cipós e palmeiras, localizadas ao longo dos rios e igarapés até $170 \mathrm{~m}$ de altitude com influência de inundações (FEO sub-tipo 4), e em sub-montanha em relevo colinoso com altitude abaixo de $400 \mathrm{~m}$ (FEO sub-tipo 3).

$\mathrm{Na}$ área de influência do Projeto Salobo o monitoramento biológico (BRANDT 1998, 2003) identificou grande diversidade faunística, incluindo representantes dos principais grupos: ictiofauna, herpetofauna, avifauna, mastofauna e odonatofauna. A maioria das espécies inventariadas localiza-se em áreas de aluvião e de matas ao longo dos cursos d'água e no relevo colinoso, sendo alvos de caça e pesca. No topo dos morros e encostas apresentam menor frequência, possivelmente por ser uma área mais seca. Muitas espécies provavelmente faziam parte da dieta alimentar dos antigos ocupantes desta área, convém ressaltar que não é coincidência que a maioria dos sítios arqueológicos ocorre também nas áreas planas localizadas nas matas ao longo dos rios e igarapés.

A área da pesquisa apresenta, pois, uma extensa malha hidrográfica circundada por Floresta Aberta Aluvial em contato com Floresta Equatorial Ombrófila aberta mista, este quadro, associado à heterogeneidade microclimática, propicia o alto índice de diversidade da fauna e da flora registrado. Sem dúvida, todos estes aspectos ambientais favoreceram o estabelecimento de contingentes populacionais na área, considerando que o ambiente na ocasião do estabelecimento dessas populações tenha sido minimamente semelhante.

\section{Aspectos históricos e as pesquisas arqueológicas na região Sudeste do Pará}

As primeiras informações sobre essa região foram escritas pelo padre Manuel da Mota, que esteve em visita às aldeias indígenas do baixo Itacaiúnas e Parauapebas em 1721. Entre 1895 e 1896 Henri Coudreau realizou o levantamento geográfico dos citados rios, reportando-se a entradas e ocupações de alguns trechos do baixo Itacaiúnas e Parauapebas (Coudreau 1980).

Na primeira década do século XX relatos de Manuel Pernambuco da Gama, que esteve na região mantendo contato com os índios Kaiapó-Xikrin do alto Itacaiúnas / Cateté, reportam a existência de populações ribeirinhas no alto curso do rio Itacaiúnas. Na década de 1960 o território Xikrin no alto curso do Itacaiúnas foi invadido e saqueado por exploradores atraídos pelos grandes castanhais da região (Silveira \& Lopes 2002).

A partir de 1967 a história da ocupação na região sudeste do Pará sofreu uma grande reviravolta. Nesse ano, com a descoberta casual de minério de ferro na serra Norte, começou a ser evidenciado o grande potencial de recursos minerais, sucedendo-se descobertas de jazidas de manganês (1971), bauxita (1974), cobre (1977), ouro (1980) e níquel (1984) na região de Carajás (Simões 1986).

Por outro lado, o potencial arqueológico começou a ser revelado em 1963 por Protásio Frikel, antropólogo do Museu Paraense Emílio Goeldi que pesquisou os índios Xikrin do alto Itacaiúnas / Cateté. Durante sua estada na área, Frikel coletou material cerâmico e lítico nas localidades Aldeia Velha do Cateté, Aldeia Nova Xikrin, Alto Bonito, Carrasco e Encontro (Frikel 1963, 1968) e percebeu, uma vez que os Xikrin não produziam cerâmica, que tais vestígios eram provenientes de outras etnias, relacionando-os aos Tupis (Frikel 1968). Esta 
coleção de peças arqueológicas, depositada no Museu Goeldi, foi posteriormente analisada pelo antropólogo Napoleão Figueiredo, que levantou a hipótese de o material ser relacionado à tradição arqueológica Tupiguarani através da definição da fase Itacaiúnas (Figueiredo 1965).

Além desses vestígios, Frikel obteve dos Xikrin informações sobre um tipo de moradia arcaica dos antigos Kuben Kamrek-ti, ancestrais dos que habitavam a área do Itacaiúnas / Cateté antes do domínio Kaiapó. Estas habitações eram buracos cavados na terra em lugares altos, a salvo de águas e enxurradas (Frikel 1968). Tais informações podem se referir às grutas e abrigos sob rocha existentes nas serras da região e que foram utilizadas tanto por grupos caçadores-coletores quanto por grupos ceramistas (Silveira 1994; Magalhães 1995b).

No início da década de 1980, em decorrência da implantação do Projeto Ferro Carajás da CVRD, tiveram início as primeiras pesquisas arqueológicas sistemáticas no sudeste do Pará. O subprojeto Salvamento Arqueológico em Carajás, coordenado por Mario F. Simões (Silveira et al. 1985; Simões et al. 1985), foi desenvolvido no âmbito de um amplo projeto de pesquisas ambientais composto por diversos subprojetos envolvendo botânica, geologia, zoologia e arqueologia intitulado "Estudo e Preservação de Recursos Humanos e Naturais da Área do Projeto Ferro Carajás". ${ }^{1}$

Os trabalhos de arqueologia seguiram a metodologia adotada pelo PRONAPABA, tendo como objetivo o cadastro de novos sítios arqueológicos, definição de fases e tradições nos contextos identificados, assim como o estabelecimento de seqüências seriadas baseadas na análise dos atributos tempero e decoração do material cerâmico (Simões 1986; Simões et al. 1973).

(1) Desenvolvido pelo Museu Paraense Emílio Goeld (MPEG - MCT) através de convênio firmado entre a Companhia Vale do Rio Doce (CVRD), o Conselho Nacional de Desenvolvimento Científico e Tecnológico $(\mathrm{CNPq})$ e a Fundação de Amparo e Desenvolvimento da Pesquisa (FADESP).
Neste projeto foram localizados e pesquisados 53 sítios arqueológicos pertencentes a dois contextos culturais datados em períodos distintos - um pré-cerâmico e outro cerâmico (Lopes et al. 1988; Silveira et al. 1985). Destes, dois sítios localizados em grutas ${ }^{2}$ foram datados no período denominado pré-cerâmico e 51 , localizados às margens dos rios Itacaiúnas, Parauapebas e seus afluentes, foram relacionados ao período cerâmico, cuja ocupação foi datada entre os séculos III e XVI da era cristã segundo datações radiocarbônicas obtidas à época (Lopes et al. 1988; Silveira 1994).

O período correspondente à ocupação mais antiga na região de Carajás está relacionado a grupos caçadores-coletores que, de acordo com datações C14, remonta a mais de 8.000 anos AP (Kipnis et al. 2005; Lopes et al. 1988; Magalhães 2005; Silveira 1994; Silveira, Rodrigues et al. 2008).

Até os anos 1990 o empreendimento Ferro Carajás foi o único a contar com um projeto arqueológico sistemático realizado no sudeste do Pará, sendo que em seu âmbito também foram desenvolvidos projetos acadêmicos (Magalhães 1995b; Silveira 1994). No decorrer da década de 1990 pesquisas de contrato localizaram outros 15 sítios arqueológicos relacionados ao período pré-cerâmico em diversas grutas na região de Carajás (Magalhães 1994, 1995a).

Vestígios pré-cerâmicos (artefatos líticos lascados, confeccionados em quartzo, citrino, ametista, quartzito, silexito etc., como raspadores, afiadores, furadores/buris, ponta de flecha e lascas) semelhantes aos identificados na Serra Norte de Carajás (Silveira \& Lopes 1993) foram encontrados na Serra das Andorinhas e Serra Sul de Carajás, indicando a presença de uma possível ramificação do referido contexto mais a sul do estado do Pará (Kern et al. 1992; Kipnis et al. 2005).

A partir de 2000, em consequência da expansão econômica nesta região, os projetos

(2) PA-AT-69: Gruta do Gavião e PA-AT-70: Gruta do N1, nos platôs N4 e N1 respectivamente (Silveira 1994; Magalhães 1995b). 
Prospecção arqueológica em áreas de floresta - contribuição metodológica da pesquisa na área do Projeto Salobo (Pará). Revista do Museu de Arqueologia e Etnologia, São Paulo, 19: 155-178, 2009.

de contrato para prospecção e salvamento arqueológicos multiplicaram-se, sendo desenvolvidos em áreas adjacentes como Canaã dos Carajás (Projeto Sossego), Cobre 118, Serra Sul, Serra Leste e na região do município de Marabá (Caldarelli et al. 2005; Kipnis et al. 2005; Magalhães 1995b, 2001; Pereira 2003a, 2003b; Silveira et al. 2003a, 2003b, 2004, 2005a, 2005b, 2006, 2008; Silveira \& Rodrigues 2005, 2006a, 2006b, 2007a, 2007b, entre outros). Nessas áreas foram encontrados vestígios semelhantes aos registrados em Carajás, relacionados tanto ao período cerâmico quanto ao pré-cerâmico. Todavia, apenas recentemente os primeiros resultados e sínteses destes trabalhos foram publicados (Almeida 2008; Almeida \& Garcia 2007, 2008; Caldarelli et al. 2005; Garcia \& Almeida 2007; Kipnis et al. 2005; Silveira, Rodrigues et al. 2008).

Em suma, apesar do incremento nos estudos recentes, o sudeste paraense é ainda arqueologicamente pouco conhecido (Kipnis et al. 2005). Trabalhos nos quais correlações espaciais, cronológicas e estilísticas nos contextos de áreas adjacentes ao sudeste paraense, da região Amazônica ou não, foram publicados há apenas três anos.

Contudo, estas incipientes pesquisas apontam a importância desta área para o melhor entendimento tanto do processo inicial da ocupação humana da Amazônia (Caldarelli et al. 2005; Kipnis et al. 2005; Silveira, Rodrigues et al. 2008), quanto do desenvolvimento e dispersão dos grupos relacionados à tradição Tupiguarani na Amazônia (Almeida 2008; Almeida \& Garcia 2007, 2008; Garcia \& Almeida 2007; Pereira et al. 2008).

\section{Metodologia da prospecção arqueológica}

Araujo (2001) aponta a escassez na bibliografia de trabalhos acerca de métodos para o levantamento arqueológico especificamente em áreas florestadas. As poucas exceções empreendem relatos de experiências utilizando, basicamente, modelos de levantamento dito sistemático ou probabilístico (Alexander 1983; Neves 1984; Spurling 1980; Zeidler 1995).
Principalmente na arqueologia da América do Sul a falta de discussões a esse respeito se torna um contrassenso, uma vez que grande parte do continente ainda hoje se encontra sob densas florestas, que progressivamente estão sendo exploradas pelo avanço da sociedade nestas áreas. Somente no Brasil a implantação de empreendimentos mineradores e hidroelétricos nestas áreas nas duas últimas décadas mais que dobrou a demanda de levantamentos arqueológicos contratados nos Estudos de Impacto Ambiental. Portanto, faz-se necessária a discussão no âmbito acadêmico das estratégias utilizadas nestes trabalhos.

Este artigo objetiva apresentar o levantamento arqueológico realizado na área do projeto minerador Salobo, em cuja investigação foram utilizadas abordagens sistemáticas, por meio da abertura de transects equidistantes entre si, e oportunísticas através da análise de indicadores ambientais como relevo, vegetação, fontes de água, entre outros. A investigação sistemática orientada por critérios ambientais, aliada a uma estratégia oportunística de levantamento de informações, auxiliou na identificação de sítios arqueológicos, otimizando o tempo em campo.

$\mathrm{Na}$ adequação da metodologia adotada para realização da prospecção arqueológica foram consideradas as características ambientais das áreas a serem afetadas pelo empreendimento, assim como a experiência adquirida com pesquisas em áreas adjacentes (Simões 1983; Pereira \& Machado 2001). Desta forma, foram efetuadas tanto análises cartográficas quanto a releitura dos procedimentos empregados e dos resultados obtidos nas pesquisas arqueológicas realizadas anteriormente na região.

Para a realização do levantamento arqueológico na área do Projeto Salobo a equipe foi dividida em dois ou quatro grupos, nos quais um auxiliar de campo acompanhava um ou dois arqueólogos. No período de 2003 a 2005 foram realizadas nove etapas de campo, totalizando 200 dias de trabalho. A área total do empreendimento é estimada em cerca de $175 \mathrm{~km}^{2}$, contudo foram prospectados os locais das obras de infraestrutura assinaladas segundo a versão atualizada do Plano Diretor fornecido pelo 
empreendedor, perfazendo um total de $80 \mathrm{~km}^{2}$ distribuídos em 30 áreas de impacto, o que corresponde a $45 \%$ da área total do Projeto.

No decorrer do trabalho foi observado que os sítios arqueológicos identificados estão distribuídos em três sub-bacias hidrográficas. A sub-bacia com maior área e quantidade de sítios arqueológicos registrados foi a do igarapé Salobo, com 12 sítios em $11 \mathrm{~km}^{2}$, em seguida está a do rio Cinzento com cinco sítios arqueológicos em uma área de $7 \mathrm{~km}^{2}$ e por último a do igarapé Mirim, com cinco sítios arqueológicos em $3 \mathrm{~km}^{2}$.

A análise dos dados cronológicos, de implantação na paisagem, bem como a caracterização da cultura material dos 22 sítios arqueológicos localizados têm possibilitado a identificação da organização do espaço intrasítio e de áreas de atividades específicas, assim como dos sistemas de assentamento dos grupos humanos que ocuparam esta área ao longo de 6000 anos. Estas informações, em processamento final, serão publicadas brevemente (Fig. 2).

Diversos autores têm-se dedicado a estudar a eficiência das técnicas de investigação para localização de sítios arqueológicos (Ćhartkoff 1978; Krakker et al. 1983; Lightfoot 1986; Kintigh 1988). Os resultados alcançados por eles, assim como a experiência em diversos projetos que utilizaram essas técnicas (Araújo Costa \& Caldarelli 1988; Guapindaia 2000, 2001; Machado 2004, 2005; Pereira 2001, entre outros), atestam sua eficácia.

A metodologia adotada para prospecção na área do Salobo teve a preocupação de interferir o mínimo possível nos sítios arqueológicos, preservando-os para investigações detalhadas futuras. Uma vez identificado, a localização do sítio foi georreferenciada através de GPS posicionamento tridimensional (3D), anotando-se a margem de erro (o DATUM utilizado foi o South America'69).

Também foram efetuados registros fotográficos e de informações como dimensões prováveis, tipo de material arqueológico e sua ocorrência em superfície e em sub-superfície em fichas de campo especialmente elaboradas para o registro das informações de forma padronizada (Figs. 3 a 5). Cabe destacar que os métodos de investigação de sub-superfície, como tradagens, só foram utilizados quando não havia vestígios arqueológicos na superfície do terreno.

Todos os sítios identificados foram plotados no mapa do Plano Diretor e em mapas topográficos detalhados, com curvas de nível de $5 \mathrm{~m}$ ou 1 $\mathrm{m}$. Efetuou-se ainda o registro na Ficha de Cadastro Nacional de Sítios Arqueológicos (CNSA) do IPHAN onde são anotadas também informações sobre o ambiente em que o sítio está inserido.

\section{Prospecção sistemática}

A prospecção sistemática consistiu na investigação do terreno de forma padronizada através da abertura de transects, ou picadas, na mata em intervalos regulares de 50 metros, ${ }^{3}$ nas quais foram observadas a superfície e subsuperfície através de tradagens realizadas a intervalos de também $50 \mathrm{~m}$. O solo retirado foi vistoriado com o auxílio de colher de pedreiro na busca de vestígios arqueológicos. Em fichas específicas (Fig. 3) foram registradas características do solo tais como textura, compactação, granulometria e coloração, descrito a partir da carta de cores para solo Munsell (1964) (Fig. 6).

As características do solo foram relacionadas com a compartimentação topomorfológica observada localmente e nos mapas detalhados. Convencionou-se utilizar os termos "topo", "alta vertente", "média vertente" e "baixa vertente" para descrição do relevo associado ao solo. Essas informações possibilitaram uma avaliação preliminar do entorno em caso de ocorrência de vestígios arqueológicos.

O registro fotográfico procurou ser o mais completo possível, mostrando o ambiente onde se inserem os vestígios observados na superfície, coloração do solo, perfis, entre outros. Nas fichas de tradagens, além das informações mencionadas acima, foram feitas anotações em relação aos indicadores de limites naturais percebidos na paisagem. Os mapas topográficos com a localização das obras, em curvas de nível

(3) O intervalo entre os transects variou em algumas áreas, aproveitando picadas já existentes para outros fins, tais como topografia e levantamento florestal. 
Prospecção arqueológica em áreas de floresta - contribuição metodológica da pesquisa na área do Projeto Salobo (Pará). Revista do Museu de Arqueologia e Etnologia, São Paulo, 19: 155-178, 2009.

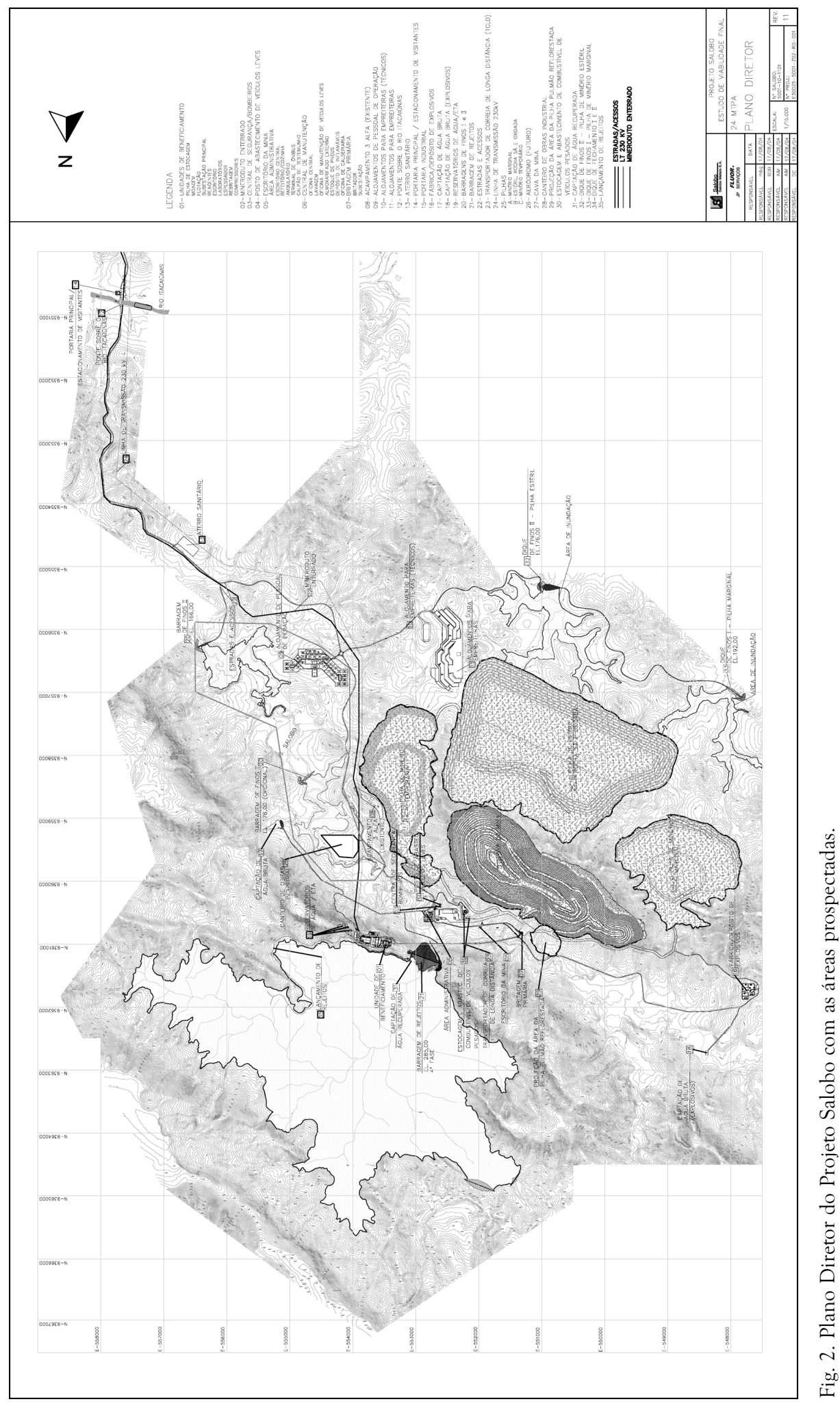




\begin{tabular}{|c|c|c|c|c|c|}
\hline \multicolumn{6}{|c|}{$\begin{array}{l}\text { PROJETO: SALOBO } \\
\text { ÁREA DE PROSPECÇÃO: } \\
\text { Mapa de referência/autor: } \\
\text { Observações Gerais (vegetação, uso atual) }\end{array}$} \\
\hline \multirow[t]{4}{*}{ 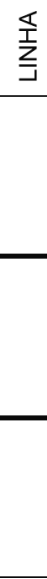 } & 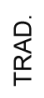 & PROF.(CM) & MUNSELL & DESCRIÇÃO SOLO & $\begin{array}{l}0 \\
\frac{\alpha}{\alpha} \\
>\end{array}$ \\
\hline & & $\begin{array}{l}\text { O/ } \\
\text { ( ) baixa.vert ( } \\
\text { OBS: }\end{array}$ & média.vert ( ) & $\begin{array}{l}\text { ( ) argiloso ( ) argilo-arenoso ( ) arenoso ( ) areno-argiloso ( ) cascalho ( ) laterita } \\
\text { ( ) argiloso ( ) argilo-arenoso ( ) arenoso ( ) areno-argiloso ( ) cascalho ( ) laterita } \\
\text { ( ) argiloso ( ) argilo-arenoso ( ) arenoso ( ) areno-argiloso ( ) cascalho ( ) laterita } \\
\text { alta.vert ( ) ingrime ( ) inclin.média ( ) inclin.suave ( ) terraço ( ) patamar ( ) inund. }\end{array}$ & \\
\hline & & $\begin{array}{l}\text { O/ } \\
\text { ( ) baixa.vert ( } \\
\text { OBS: }\end{array}$ & média.vert ( ) & $\begin{array}{l}\text { ( ) argiloso ( ) argilo-arenoso ( ) arenoso ( ) areno-argiloso ( ) cascalho ( ) laterita } \\
\text { ( ) argiloso ( ) argilo-arenoso ( ) arenoso ( ) areno-argiloso ( ) cascalho ( ) laterita } \\
\text { ( ) argiloso ( ) argilo-arenoso ( ) arenoso ( ) areno-argiloso ( ) cascalho ( ) laterita } \\
\text { alta.vert ( ) ingrime ( ) inclin.média ( ) inclin.suave ( ) terraço ( ) patamar ( ) inund. }\end{array}$ & \\
\hline & & $\begin{array}{l}0 / \\
\text { ( ) baixa.vert ( } \\
\text { OBS: }\end{array}$ & nédia.vert ( & $\begin{array}{l}\text { ( ) argiloso ( ) argilo-arenoso ( ) arenoso ( ) areno-argiloso ( ) cascalho ( ) laterita } \\
\text { ( ) argiloso ( ) argilo-arenoso ( ) arenoso ( ) areno-argiloso ( ) cascalho ( ) laterita } \\
\text { ( ) argiloso ( ) argilo-arenoso ( ) arenoso ( ) areno-argiloso ( ) cascalho ( ) laterita } \\
\text { alta.vert ( ) ingrime ( ) inclin.média ( ) inclin.suave ( ) terraço ( ) patamar ( ) inund. }\end{array}$ & \\
\hline
\end{tabular}

Fig. 3. Ficha para registro das tradagens.

de $1 \mathrm{~m}$, possibilitaram análise prévia do relevo e da hidrografia desses locais e auxiliaram no estabelecimento dos transects (Fig. 7).

Posteriormente esses dados foram sintetizados em tabelas elaboradas no programa Excel a fim de agrupar e quantificar informações como numeração dos transects e das tradagens, tipo e quantidade de vestígios arqueológicos registrados, coloração do solo, relevo/compartimentação topográfica, cursos d'água mais próximos, além de observações específicas de cada local investigado.

Para a prospecção sistemática em obras lineares, como as Estradas, o Transportador de Correia de Longa Distância (TCLD) e a Linha de transmissão (LT), foram abertos transects equidistantes em 50 metros transversais ao eixo traçado. Estes transects tiveram no mínimo 50 metros de extensão para cada lado do eixo prospectado, cobrindo assim uma faixa mínima de 100 metros de largura. Nestes foram realizadas tradagens também a cada 50 metros, ou seja, no eixo da estrada e nas extremidades, formando assim uma malha de 50 x 50 metros.

Nos trechos em que o traçado das obras passa próximo a rios e igarapés as picadas foram prolongadas até as margens dos mesmos, de forma a cobrir áreas potencialmente propícias à ocorrência de sítios arqueológicos. Também foram prolongadas nos locais planejados para implantação de outras obras de infraestrutura próximas, de forma a cobrir integralmente as áreas diretamente afetadas.

As estradas foram integralmente cobertas, enquanto para o TCLD e a LT houve seleção amostral, com base na análise de mapas topográficos e no conhecimento da área, de trechos para realização da prospecção uma vez que a maior parte dessas obras está em áreas bastante acidentadas, como encostas muito íngremes. Para o levantamento do TCLD foi selecionado trecho com $1 \mathrm{~km}$ de extensão e para a LT dois trechos, um com 600 metros e outro com 1200 metros.

Para a prospecção sistemática na área planejada para a Barragem de Rejeitos do Mirim o intervalo entre os transects foi de 80 metros, com tradagens a cada 50 metros ao longo de cada transect, cuja extensão variou conforme o alcance do lago a ser formado. ${ }^{4} \mathrm{Na}$

(4) Considerando o espelho d'água a ser formado em 26 anos. 


\section{DADOS GERAIS \\ Projeto:Salobo}

Sítio:

Identificação e localização da sondagem :

Pesquisador resp/Equipe:

\section{DIMENSÕES}

Medidas horizontais:

Orientação:

Sub-datum usado $\mathrm{N}^{\circ}$ :

Altura:

Localização horizontal (coordenadas GPS):

Descrição da Topografia:

Vegetação:

Ferramentas utilizadas:

\begin{tabular}{|c|c|c|c|}
\hline Pincéis ( ) & vassorinha piaçava & colher de pedreiro ( ) & baldes \\
\hline trincha ( ) & espátulas de madeira & pá de lixo & pá \\
\hline colher ( ) & alicate $p /$ cortar raízes & enxadeco & trado \\
\hline faca & instrumentos de dentista ( ) & enxada & ancinho \\
\hline pinça （ ) & pauzinho de laranjeira ( ) & ferro de cova & outros \\
\hline
\end{tabular}

Peneira utilizada: $1 / 2$ ( ) $\quad 1 / 4$ ( ) $\quad 1 / 8($ ) $1 / 16$ ( )

\section{OBSERVAÇÕES:}

\section{PERFIL}

desenhista:

desenho $n^{\circ}$

escala:

parede:

sub-datum:

conteúdos observados/legenda

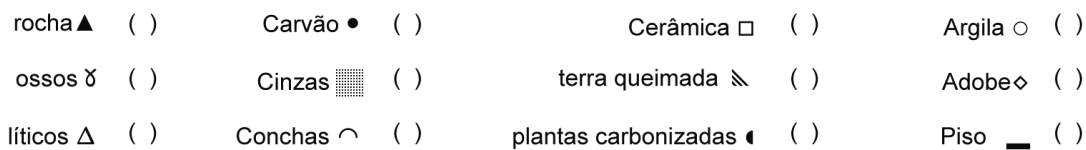

outros ( )

amostras recolhidas no perfil:

C-14 ( ) pólen ( ) flotação ( ) outros ( )

Foto PB( ) colorida ( ) slide( ) digital( ) Polaroid( ) Vídeo( ) desenho( )

Descrição das camadas, manchas e lentes:

- unidades estratigráficas (letra e/ou número):

- cor (descritiva e Munsell)

- textura

- compactação

- dureza

- umidade

- perturbações

- correlação entre os níveis e as camadas

Fig. 4. Ficha para registro da abertura de sondagens. 


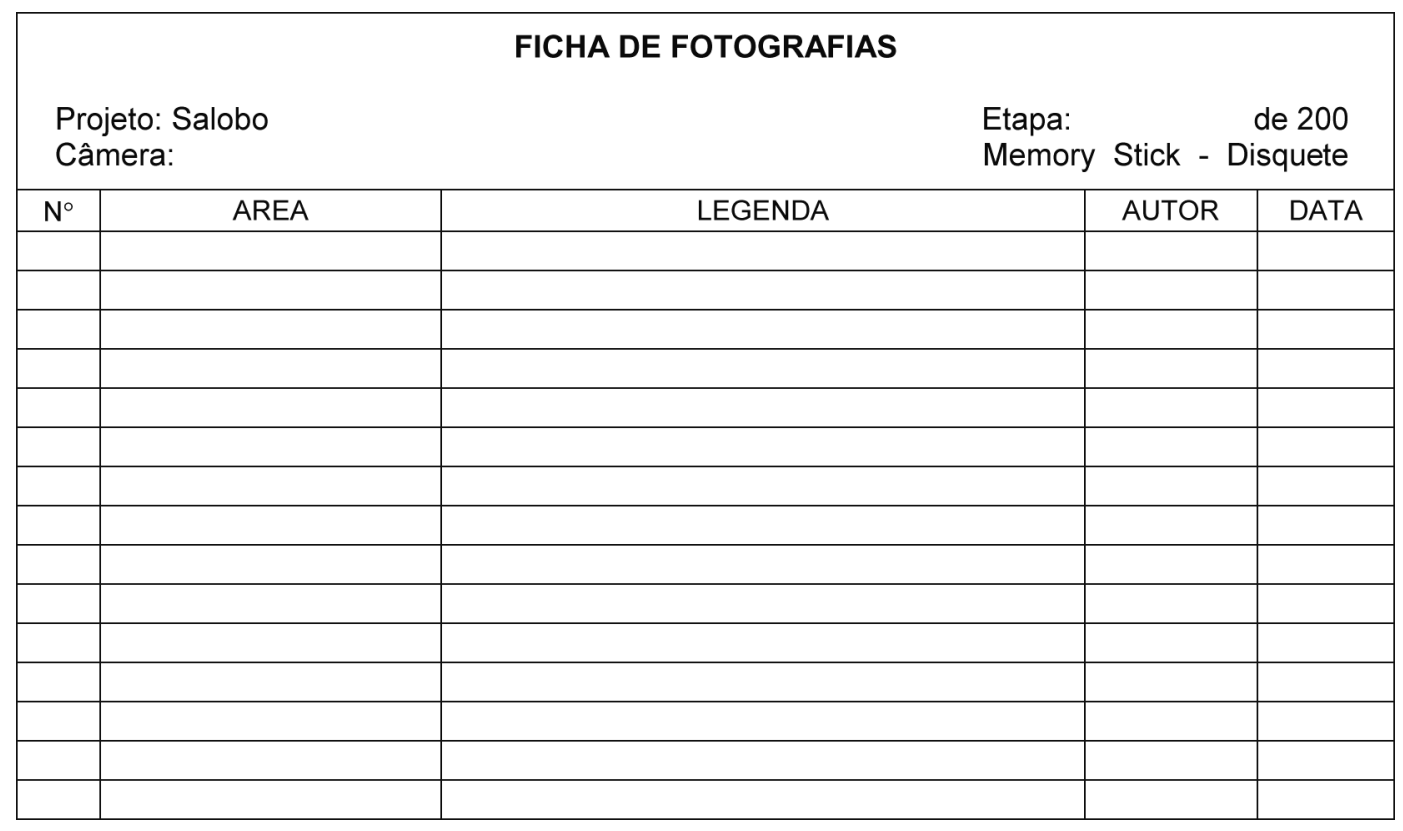

Fig. 5. Ficha para cadastro fotográfico.

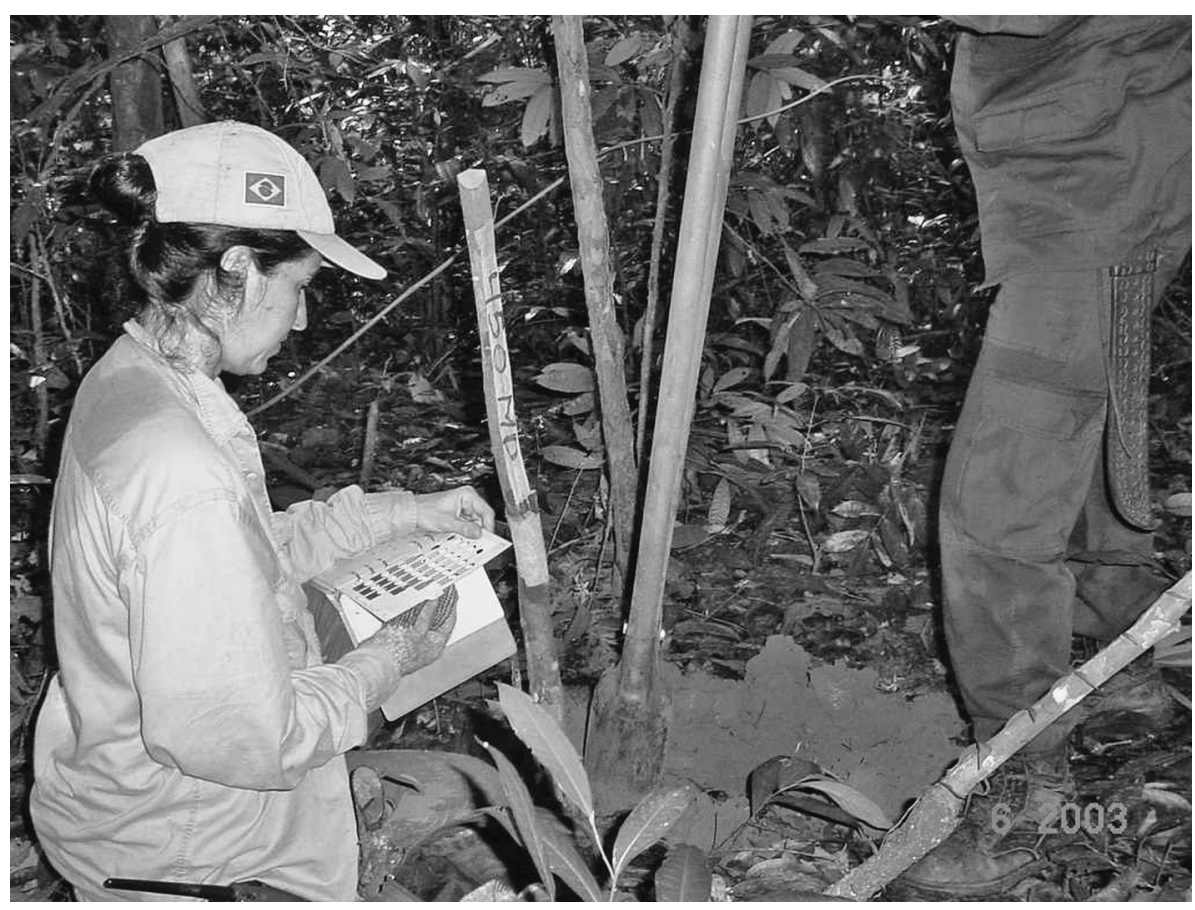

Fig. 6. Registro das características do solo.

área mais próxima ao Dique da Barragem as picadas foram abertas a intervalos de 40 metros e as tradagens realizadas a cada 50 metros.
Já a prospecção sistemática na área dos alojamentos e dos Diques de Contenção de Finos I e II do igarapé Salobo e do rio Cinzen- 


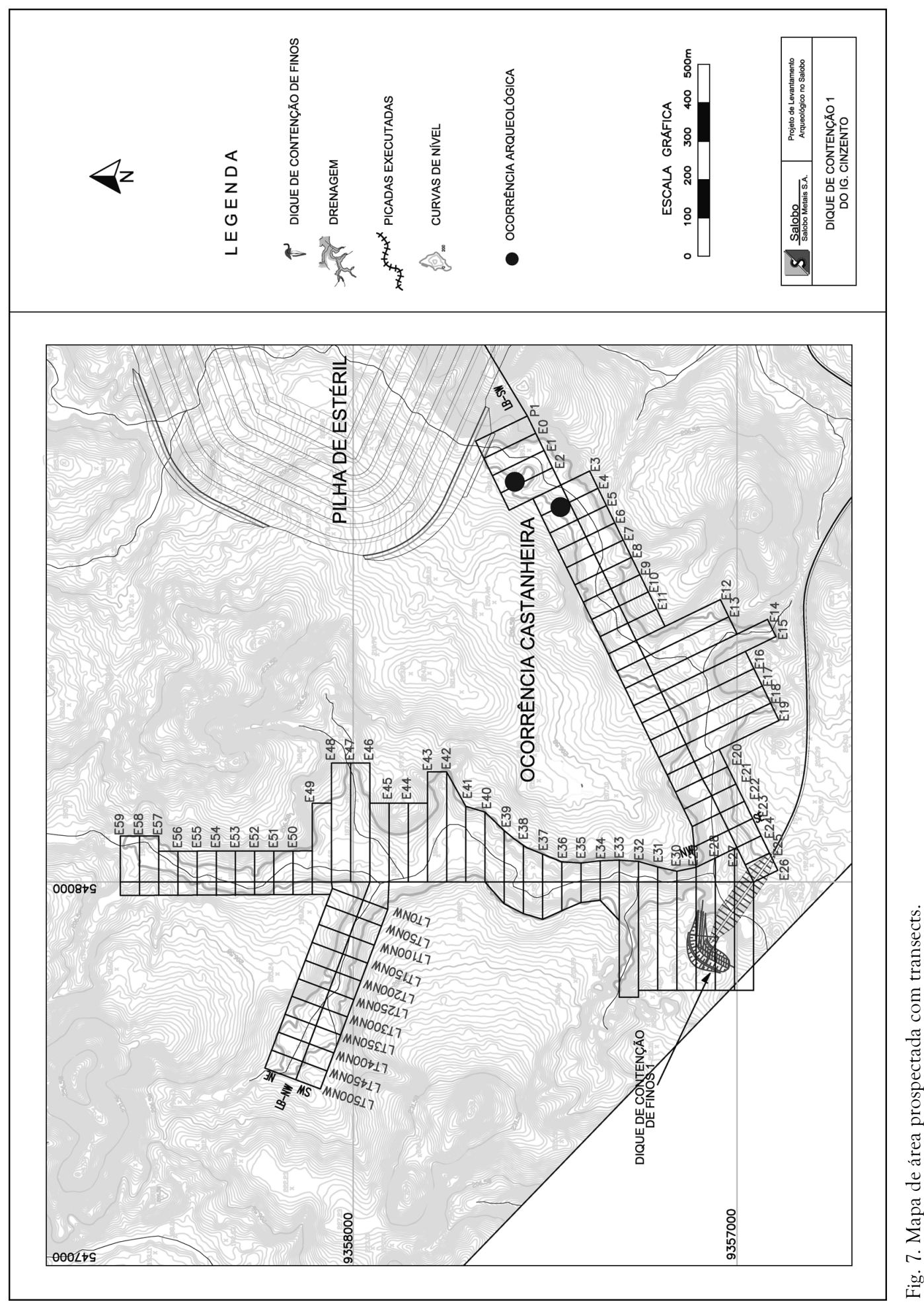


to foi feita em transects transversais abertos a intervalos de 50 metros nos quais foram efetuadas tradagens também a cada 50 metros. A prospecção abrangeu os locais previstos para construção dos alojamentos e dos diques assim como a área de inundação prevista para os mesmos.

Na área das Pilhas de Minério Temporário, Estéril e Rocha Sã e na Pilha de Minério Marginal a metodologia empregada na prospecção também seguiu o espaçamento de 50 metros para abertura dos transects paralelos, onde foram efetuadas tradagens equidistantes também em 50 metros. Nestas áreas houve seleção para prospecção sistemática, uma vez que se observa um relevo bastante acidentado com encostas muito íngremes, desfavorável ao estabelecimento de qualquer tipo de moradia ou acampamento. Dessa forma, foram cobertas as áreas próximas aos cursos d'água e de relevo mais suave, ou seja, com potencial arqueológico. Já na área contígua, Diques I e II do

Cinzento, a prospecção cobriu integralmente a área a ser afetada pela implantação dos mesmos.

A prospecção na área planejada como alternativa atual de implantação da Usina e Administração aproveitou picadas existentes para o levantamento geofísico. Essas picadas foram abertas a intervalos de 150 metros cobrindo o topo da serra e, desta forma, vertentes bastantes íngremes além do platô. As tradagens seguiram o espaçamento de 50 metros nas linhas transversais e linha base, que corta o topo da serra como um transect. Dessa forma, essa área foi vistoriada em uma combinação das abordagens sistemática e oportunística, uma vez que a localização dessas obras ainda não estava completamente definida na ocasião da pesquisa.

\section{Prospecção oportunística}

Aliada à prospecção sistemática foram adotadas abordagens oportunísticas. Em locais com baixa probabilidade de serem encontrados vestígios arqueológicos, porém com previsão de implantação de obras do empreendimento, esta estratégia foi adotada. Nestes casos incluem-se áreas de relevo muito acidentado ou alagado e outras em que o solo foi exposto naturalmente por buracos de árvores e animais e também por atividades antrópicas, como antigas trilhas de garimpeiros, poços de sondagem geológica, perfis de estradas, áreas de empréstimo, picadas abertas pelo levantamento topográfico.

Esta abordagem foi igualmente utilizada em locais a princípio não diretamente afetados pela implantação do empreendimento, mas com potencial para ocorrência de vestígios arqueológicos. A investigação de áreas propícias para habitação a partir da observação de indicadores ambientais aproveitou a exposição do solo pela ação de elementos naturais como barrancos fluviais, buracos de animais e árvores, formações rochosas junto aos cursos d'água (pedrais) e abrigos, assim como locais com intervenção antrópica anterior (estradas, poços, trilhas de garimpeiros etc.).

A prospecção oportunística também considerou informações orais de possíveis vestígios arqueológicos obtidas com terceiros, como funcionários das empresas e antigos moradores.

\section{Sítios e ocorrências arqueológicas}

Foram definidos como sítios arqueológicos locais com vestígios de Terra Preta Arqueológica (TPA), fragmentos de peças cerâmicas e líticas (lascadas e/ou polidas) em quantidade suficiente para caracterizar uma ocupação humana de longa duração. $\mathrm{O}$ critério utilizado foi a existência de ao menos 15 fragmentos cerâmicos ou vestígios líticos em contexto de deposição primária. No caso de vestígios em suportes fixos, como polidores, afiadores ou arte rupestre, esse quantitativo não foi considerado.

As ocorrências arqueológicas, por sua vez, são locais em que foram identificados vestígios arqueológicos em quantidade insuficiente para caracterizar de imediato um sítio arqueológico. O critério utilizado para sua definição foi a existência de uma concentração de vestígios inferior a 15 fragmentos cerâmicos ou líticos e/ ou de estes terem sido identificados em contexto de deposição secundária. 


\section{Verificação das ocorrências e delimitação preliminar dos sítios arqueológicos}

Concluído o levantamento em uma área pesquisada, a equipe retornou aos locais onde foram registrados vestígios arqueológicos a fim de verificar, com uma investigação mais intensiva, se estes serão registrados como sítios arqueológicos ou como ocorrências isoladas.

Em cada local de ocorrência foram realizadas varreduras com a utilização de forquilhas para identificação da distribuição de material em superfície. Para observação de sub-superfície foram realizadas tradagens equidistantes a intervalos variáveis conforme cada caso específico $(20 \mathrm{~m}, 10 \mathrm{~m}$ ou $5 \mathrm{~m})$. Foram também abertos transects intermediários para varreduras e tradagens a espaçamentos menores, delimitando de forma mais precisa a área de dispersão dos vestígios. No caso em que o número de vestígios se manteve inferior a 15 fragmentos e sem outros indicativos, o registro foi mantido como ocorrência arqueológica.

Após essa investigação, quando caracterizado como sítio arqueológico, foi realizada ao menos uma sondagem para verificação da estratigrafia, ocorrência de material em profundidade e, se possível, coleta de material in situ para datação. As sondagens foram abertas com dimensões de $50 \times 50 \mathrm{~cm}$ ou $1 \mathrm{~m}$ x $1 \mathrm{~m} \mathrm{e}$ escavadas com colher de pedreiro por níveis naturais. Após o término da ocorrência de evidências arqueológicas foram escavados outros $20 \mathrm{~cm}$ e finalmente, por medida de segurança, realizou-se uma tradagem na base alcançando mais $50 \mathrm{~cm}$ na camada estéril. $\mathrm{O}$ solo retirado de cada nível foi peneirado separadamente em peneira de malha $5 \mathrm{~mm}$ a fim de que pudessem ser coletados vestígios eventualmente não percebidos durante a escavação.

Todas as informações foram registradas em fichas de sondagem (Fig. 4) nas quais foram anotadas as características do solo (composição, compactação, granulação, umidade e coloração Munsell), dados como o georreferenciamento (GPS), tipos de vestígios arqueológicos encontrados, quantidade e espessura dos níveis escavados, definição de camadas, entre outras informações.
Uma vez encerrada a escavação da sondagem, as quatro paredes foram fotografadas com escala e indicação do Norte, sendo geralmente duas paredes selecionadas para desenho do perfil. Nos perfis foram definidas e descritas as camadas estratigráficas através da descrição da espessura, características do solo e vestígios associados. Efetuou-se também a correlação dos níveis escavados com as camadas estabelecidas. O estudo dos perfis serviu de base para compreensão da estratigrafia de cada sítio, bem como planejamento de futuras escavações (Figs. 8 e 9).

Em todos os sítios registrados, após exame cuidadoso da superfície, foi verificada preliminarmente a dispersão dos vestígios arqueológicos em sub-superfície, assim como a espessura das camadas arqueológicas. Foram abertas linhas radiais ou paralelas a partir do ponto de maior concentração de material e realizadas novas tradagens a cada $5 \mathrm{~m}$ ou $2 \mathrm{~m}$. Também foram elaborados croquis com a distribuição dos vestígios observados, das tradagens, sondagens (quando efetuadas), além de anotações, em fichas padronizadas, marcando-se, sempre que observados, os indicadores de limites naturais percebidos na paisagem. Dessa forma foi possivel estabelecer uma delimitação preliminar das dimensões e profundidade dos sítios arqueológicos localizados. As informações registradas nos croquis, sobrepostas aos mapas topográficos, permitiram avaliação e planejamento mais precisos para os trabalhos de salvamento (Fig. 10).

Para cada sítio realizou-se também uma avaliação do seu estado de conservação e do impacto a que estava sujeito com a implantação do empreendimento. A partir daí foram indicadas para cada caso as medidas apropriadas a serem adotadas: preservação, o monitoramento ou salvamento (resgate).

\section{Resultados}

A metodologia adotada na prospecção realizada na área do Projeto Salobo possibilitou a localização de 22 sítios arqueológicos e cinco ocorrências, distribuídos em três sub-bacias: rio Cinzento, igarapé Salobo (tributários da 


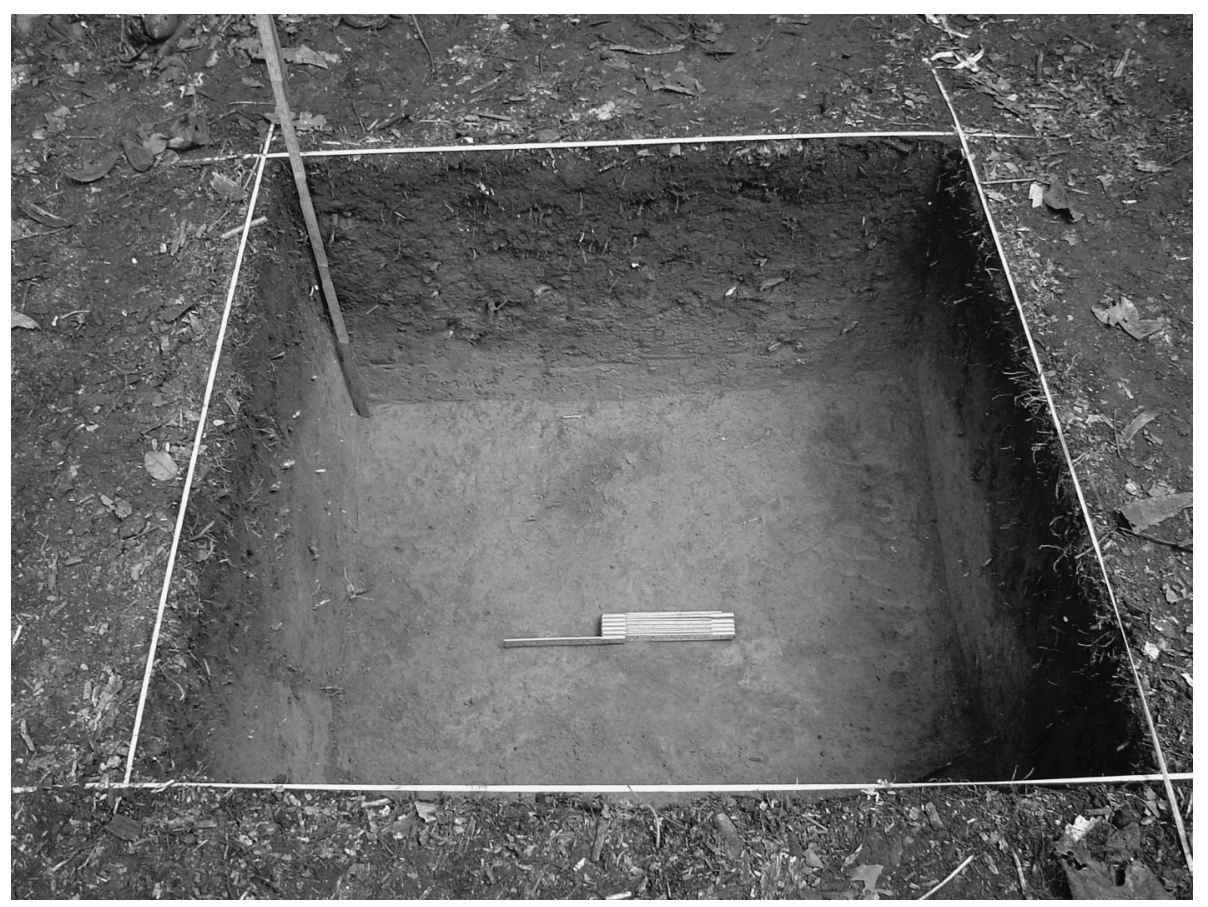

Fig. 8. Sítio Cachorro Cego. Sondagem 1. Foto Elisangela Oliveira.

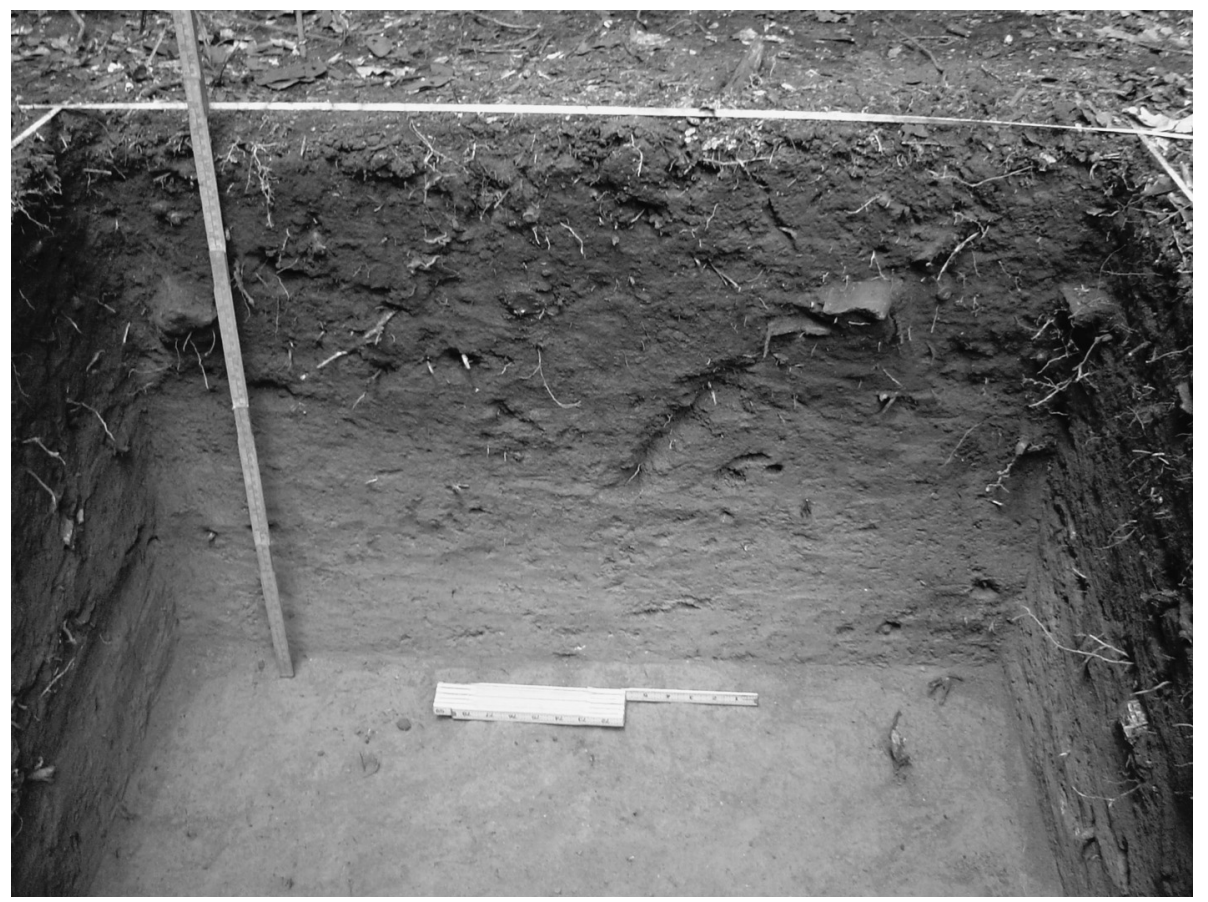

Fig. 9. Sítio Cachorro Cego. Sondagem 1 (detalhe). Foto Elisangela Oliveira. 


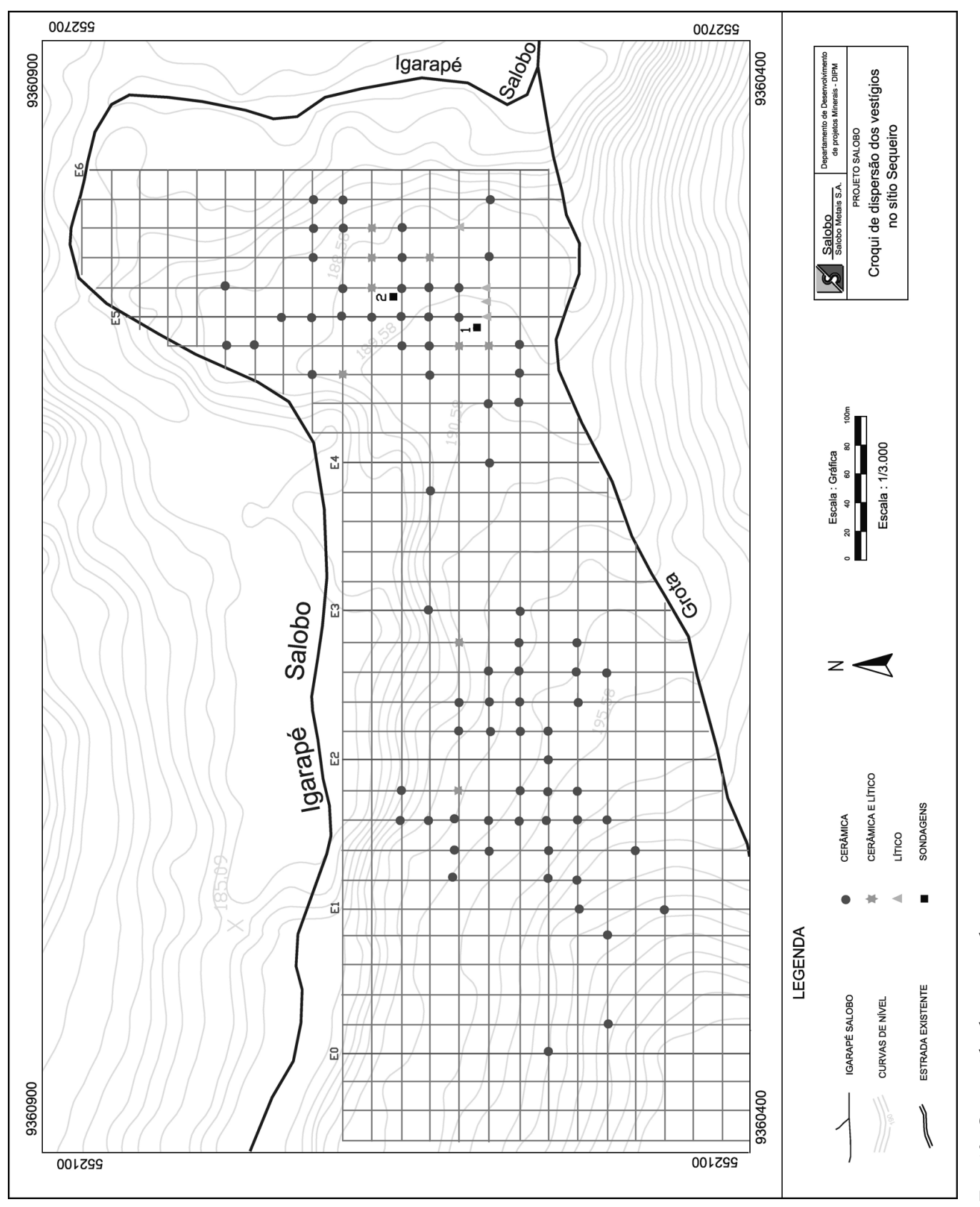

margem esquerda do rio Itacaiúnas) e igarapé Mirim (afluente da margem esquerda do igarapé Salobo). Além destes, uma ocorrência situada na margem esquerda do rio Itacaiúnas também foi localizada (Fig. 11).

Na sub-bacia do igarapé Salobo foram registrados 12 sítios arqueológicos: Dique BF1,
Dique BF2, Bitoca 1, Bitoca 2, Barfi, Captação, Araras, Sequeiro, Pau Preto, P32, 4 Alfa, Alex e a ocorrência arqueológica Barfi 5. Na sub-bacia do igarapé Mirim os cinco sítios registrados foram: Cachoeira do Borges, Marinaldo, Reginaldo, Mirim e Perdido do Mirim. Na subbacia do rio Cinzento cinco sítios foram 


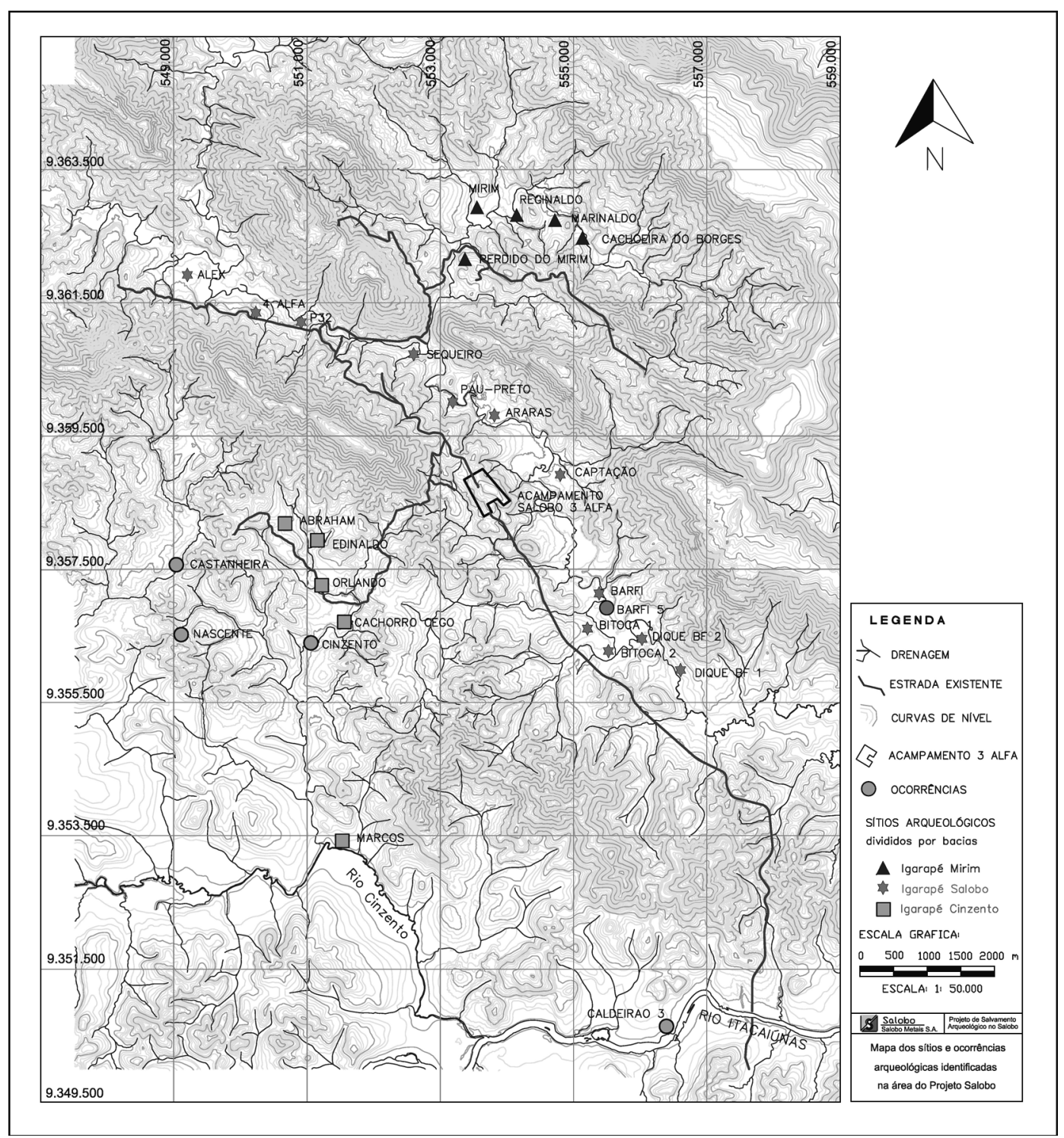

Fig. 11. Mapa dos sítios e ocorrências identificadas na área do Salobo.

registrados: Abraham, Edinaldo, Orlando, Cachorro Cego e Marcos, além das ocorrências arqueológicas Nascente, Castanheira e Cinzento. Nas margens do rio Itacaiúnas foi registrada apenas uma ocorrência, denominada Caldeirão 3 e que está relativamente próxima, porém na margem oposta, da corredeira do Caldeirão e dos sítios arqueológicos PA-AT-18: Caldeirão 1 e PA-AT-19: Caldeirão 2, registrados nos anos 80 na margem direita do Itacaiúnas (Lopes et al. 1988).
Observando a implantação dos sítios na paisagem verificou-se que, geralmente, estes se encontram delimitados naturalmente, sendo identificados como limites curvas ou meandros de rios ou igarapés, grotas (nascentes) e elevações naturais. Esta padronização, recorrentemente observada, permitiu a elaboração de um modelo preditivo para identificação prévia, através da análise de mapas topográficos detalhados, de locais propícios para o estabelecimento de sítios arqueológicos. 
Os sítios identificados foram classificados, segundo o tamanho da área de dispersão dos vestígios arqueológicos, em três categorias: 1) Pequeno, com dimensão até $25.000 \mathrm{~m}^{2}$; 2) Médio, com dimensão entre 26.000 e 85.000 $\mathrm{m}^{2}$ e 3) Grande, com dimensão superior a $86.000 \mathrm{~m}^{2}$. Foi possível observar, durante a prospecção, que os sítios pequenos não possuem TPA e que a camada arqueológica é pouco profunda, ao redor de 20 e $35 \mathrm{~cm}$ de profundidade. A hipótese de ocupação para estes sítios é de que se relacionam a áreas de habitação temporária ou acampamentos. Nos sítios medianos também não foram encontradas manchas de TPA, o solo varia entre tons de marrom escuro e marrom, porém a camada arqueológica é mais profunda, entre 35 e $60 \mathrm{~cm}$ de profundidade. Nos sítios de tamanho superior a $86.000 \mathrm{~m}^{2}$ foram encontradas manchas de TPA e a profundidade do registro arqueológico varia de $60 \mathrm{~cm}$ a $1,5 \mathrm{~m}$, possivelmente são assentamentos relacionados a ocupações de longa duração.

Associados aos sítios Bitoca 1: PA-AT-277 e Bitoca 2: PA-AT-278, de tamanho grande e Araras: PA-AT-283 e Marcos: PA-AT-297, de tamanho mediano, foram registrados em afloramentos rochosos nas margens dos cursos d'água polidores e afiadores.

A tabela abaixo foi elaborada tendo em vista uma melhor visualização da caracterização geral dos sítios e sua implantação na paisagem, constituindo-se em fonte de dados de referencia.

Desta forma, a prospecção realizada na FLONATA - área do Projeto Salobo - demonstrou que é possível identificar sítios e ocorrências arqueológicas através do desenvolvimento de investigação sistemática em extensas áreas florestadas, aliada a prospecção oportunística, mesmo com as dificuldades logísticas inerentes. Através do caminhamento intensivo e articulado na extensão de transects equidistantes abertos na floresta foi possível esquadrinhar todas as áreas que sofrerão impacto deste empreendimento minerador, identificar e analisar padrões de implantação e assentamento das sociedades pretéritas que ali viveram.

Progressivamente a pressão econômica sobre as áreas de floresta no Brasil, notadamente a
Amazônia, tem impulsionado a realização de pesquisas de levantamento e salvamento arqueológico neste tipo de ambiente, porém, ainda são raras as discussões acerca dos métodos envolvidos neste trabalho, seus alcances e limites. Debate este crucial para uma avaliação do quanto realmente tem-se conseguido documentar o patrimônio arqueológico em áreas que serão modificadas pela implantação de grandes obras. Portanto, corre-se o risco de perder contextos importantes para a compreensão do processo de ocupação humana.

\section{Considerações finais}

A metodologia aplicada na prospecção realizada entre os anos 2003 e 2006 no âmbito do projeto Prospecção arqueológica na área do Projeto Salobo/PA foi considerada adequada para o cumprimento dos objetivos propostos, permitindo a localização de sítios arqueológicos em áreas florestadas e a definição de uma tipologia preliminar dos mesmos, possibilitando, assim, a edificação de um panorama da ocupação pretérita nesta região do sudeste paraense.

A prospecção realizada nas sub-bacias do igarapé Salobo, do rio Cinzento (afluentes do rio Itacaiúnas) e do igarapé Mirim (tributário do Salobo) revelou os seguintes aspectos arqueológicos significativos desta área:

a) Identificação e localização de 22 sítios arqueológicos cerâmicos a céu aberto;

b) Tais sítios, geralmente, encontram-se localizados às margens dos cursos d'água, tanto de rios maiores, como o Itacaiúnas, como de pequenos igarapés;

c) Inserção dos sítios na paisagem com delimitadores naturais (cursos d'água, fontes e/ou nascentes, relevo com morros, afloramentos rochosos e presença de Castanhais);

d) Estabelecimento de uma tipologia preliminar para os sítios arqueológicos encontrados: habitação e acampamento;

e) Na região de Carajás a presença dos sítios cerâmicos é bastante densa, 


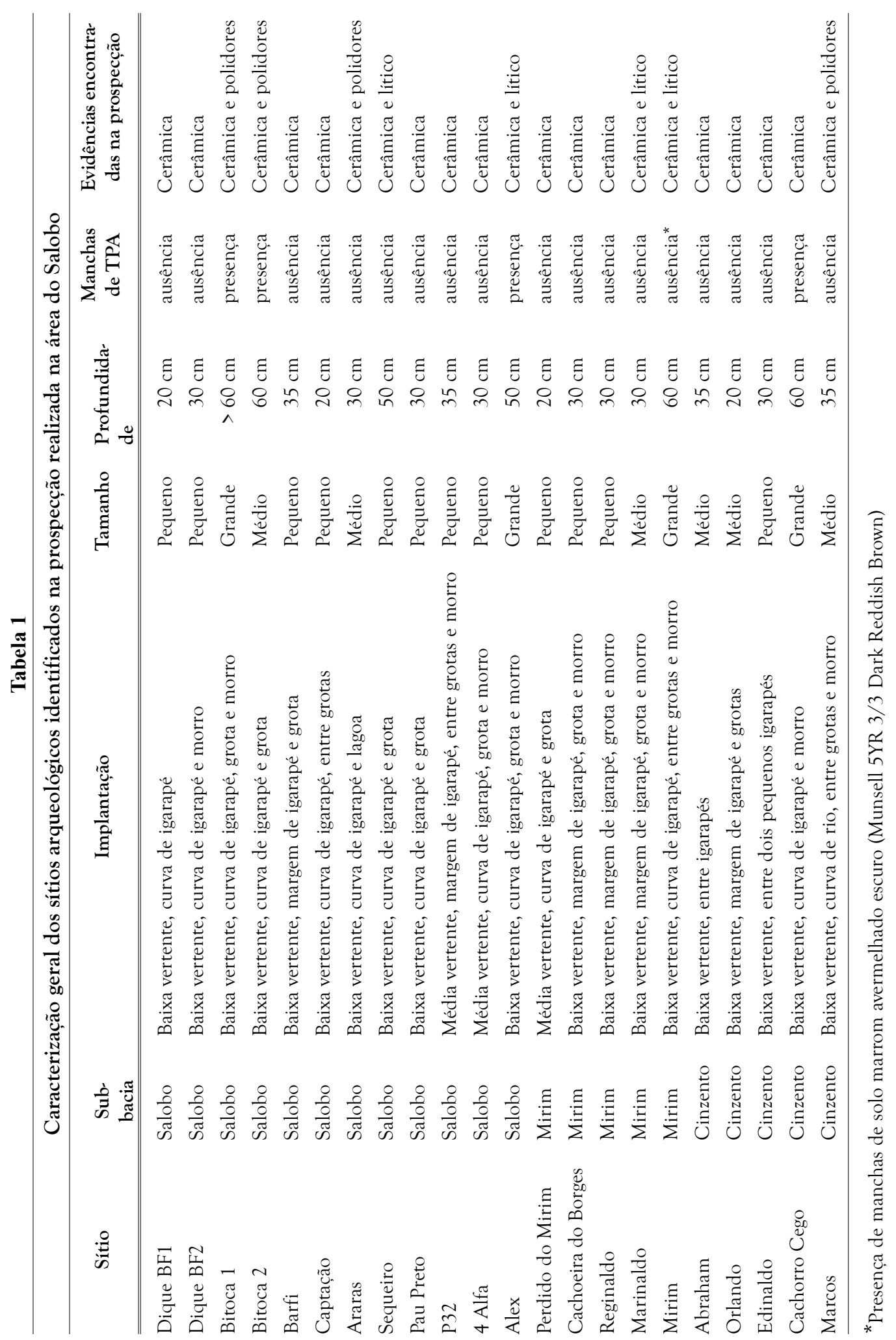


com uma média aproximada de um sítio a cada $1,2 \mathrm{~km}$. Por exemplo, nas margens do rio Itacaiúnas, no trecho mais próximo da área de implantação do projeto Salobo, existem pelo menos oito sítios arqueológicos numa extensão aproximada de $9,5 \mathrm{~km}$, registrados durante a prospecção realizada na década de 1980 (Lopes et al. 1988). Na área do Salobo também foi registrada presença densa de sítios, com uma média aproximada de um sítio a cada $1 \mathrm{~km}$;

f) A análise laboratorial indica que a indústria cerâmica relacionada aos sítios identificados na bacia do rio Cinzento e do baixo igarapé Salobo possuem características tecnológicas, morfológicas e estilísticas predominantes que remetem à tradição Tupiguarani (Brochado 1991; Prous 1992), cuja presença em sítios arqueológicos localizados na bacia do rio Itacaiúnas e em áreas adjacentes tem sido documentada desde a década de 1960 (Almeida 2008; Almeida \& Garcia 2007, 2008; Araujo Costa 1983; Garcia \& Almeida 2007; Figueiredo 1965; Pereira 2003a, 2003b; Pereira et al. 2008; Simões \& Araujo Costa 1987).

Contudo, a diversidade dos vestígios arqueológicos coletados nas escavações realizadas posteriormente nestes sítios, durante o trabalho de salvamento arqueológico, notadamente a presença de elaborados apliques cerâmicos modelados zoomorfos e um antropomorfo, além de um pingente zoomorfo polido e esculpido em rocha, indicam um quadro mais complexo para a ocupação nesta área. Os aspectos tecnológicos e decorativos destes artefatos remetem à indústria cerâmica da tradição Incisa Ponteada, da qual faz parte, por exemplo, a cerâmica Santarém (Guapindaia 1993; Gomes 2002).

Além disso, as características decorativas e tecnológicas identificadas no material cerâmico proveniente dos sítios localizados no médio igarapé Salobo e na bacia do igarapé Mirim, também diferem da fase Itacaiúnas da tradição Tupiguarani, na qual as peças são geralmente espessas e possuem grande quantidade de minerais triturados, principalmente quartzo, na pasta da argila.

Em razão de as análises dos vestígios destes 22 sítios arqueológicos estarem em andamento, discussões aprofundadas acerca das características tanto do material cerâmico, quando do material lítico, bem como hipóteses sobre a natureza e diversidade das ocupações humanas pré-coloniais na área do Salobo, serão apresentadas e discutidas em trabalhos futuros.

Espera-se que esse artigo contribua para a metodologia de prospecção arqueológica em áreas de floresta, assim como forneça dados relevantes acerca dos deslocamentos destes grupos humanos e das redes de trocas estabelecidas entre diferentes regiões.

\section{Agradecimentos}

A Salobo Metais S.A - VALE, ao Museu Paraense Emílio Goeldi (MPEG-MCT), a Fundação Instituto para o Desenvolvimento da Amazônia (FIDESA) e a todos que participaram dos trabalhos de campo. Agradecimento especial a Astolfo Araujo pelo incentivo à publicação deste trabalho e revisão do manuscrito. 
SILVEIRA, M.I.; RODRIGUES, M.C.L.; MACHADO, C.L.; OLIVEIRA, E.R.; LOSIER, L.-M. Archaeological exploration in forest areas - methodological contribution in the field of research of the Salobo Project. Revista do Museu de Arqueologia e Etnologia, São Paulo, 19: 155-178, 2009.

Abstract: Between 2003 and 2006, an archaeological survey in the Salobo Project - PA was developed by the Paraense Emilio Goeldi Museum in order to identify and assess the impacts of the implementation of mining activities of VALE Company to the archaeological heritage as well as measures to indicate their preservation or rescue. This article aims to present the methodology of archaeological survey used for the identification of archaeological remains in the National Forest Tapirapé - Aquiri (FLONATA), municipality of Marabá / PA, which will be affected by the implementation of this mine. This experience should stimulate discussions about the scope and limits of the approach presented, which resulted in the identification of 22 archaeological sites and 5 events.

Keywords: Archaeological exploration - Amazon Forest - Southeastern Pará - Salobo - archaeological survey methodology.

\section{Referências bibliográficas}

ALEXANDER, D.

1983 The limitations of traditional surveying techniques in a forested environment. Journal of Field Archaeology, 10: 177-186.

ALMEIDA, F.O. de

2008 O complexo Tupi da Amazônia Oriental. Dissertação (Mestrado) - Museu de Arqueologia e Etnologia, Universidade de São Paulo, São Paulo.

ALMEIDA, F.O. de; GARCIA, L.G.

2007 Pintura cerâmica Tupi do baixo Tocantins. In: Congresso da Sociedade de Arqueologia Brasileira: Arqueologia, Etnicidade e Território, 14, 2007, Florianópolis. Anais. $1 \mathrm{CD}$.

2008 Aspectos do espaço Tupinambá no leste Amazônico. Revista de Arqueologia, 21 (2): 97-119.

ARAUJO, A.G.M.

2001 Teoria e método em arqueologia regional: um estudo de caso no alto Paranapanema, estado de São Paulo. 2001. 2 v., il., mapas. Tese (Doutorado) - Faculdade de Filosofia, Letras e Ciências Humanas, Universidade de São Paulo, São Paulo.

ARAÚJO COSTA, F.

1983 Projeto baixo Tocantins: salvamento arqueológico na região de Tucuruí (Pará). 77 f. Dissertação (Mestrado) - Faculdade de Filosofia, Letras e Ciências Humanas, Universidade de São Paulo, São Paulo.

ARAÚJO COSTA, F.; CALDARELLI, S.B.

1988 Programa de estudos arqueológicos na área do reservatório de Kararahô (PA). Relatório de Pesquisas. Belém: Museu Paraense Emílio Goeldi.

BRANDT Meio Ambiente

1998 Documento integrado dos relatórios de zoneamento ambiental e monitoramento biológico da área de influência do Projeto Salobo. Belo Horizonte: Salobo Metais S.A.

2002a Mapeamento das áreas potencialmente erodíveis. Atendimento a condicionantes ambientais da licença prévia condicionante 3. Belo Horizonte: Salobo Metais S.A.

2002b Complementação do levantamento florístico. Atendimento a condicionantes ambientais da licença prévia condicionante 4. Belo Horizonte: Salobo Metais S.A.

2003 Plano de controle ambiental (PCA). Programa A - Descrição do empreen- 
dimento. Belo Horizonte: Salobo

Metais S.A.

BROCHADO, J.P.

1991 Um modelo ecológico de difusão da cerâmica e da agricultura no leste da América do Sul. In: Simpósio de PréHistória do Nordeste Brasileiro, 1, 1987, Recife. Anais. Clio (série Arqueológica), Recife: Universidade Federal de Pernambuco, 4: 85-88.

CALDARELLI, S.B.; ARAÚJO COSTA, F.; KERN, D.C.

2005 Assentamentos a céu aberto de caçadores-coletores datados da transição Pleistoceno final / Holoceno inicial no Sudeste do Pará. Revista de Arqueologia, São Paulo, 18: 95-108.

CHARTKOFF, J.L.

1978 Transect interval sampling in forests. American Antiquity, 43 (1): 46-53.

COMPANHIA VALE DO RIO DOCE (CVRD)

1981 Projeto Ferro Carajás. Relatório. 134 p. COUDREAU, $\mathrm{H}$.

1980 Viagem à Itaboca e ao Itacaiúnas. Belo Horizonte: Itatiaia; São Paulo: Edusp. 177 p.

FIGUEIREDO, N.

1965 A cerâmica arqueológica do rio Itacaiúnas. Boletim do Museu Paraense Emílio Goeldi, Belém, 27: 1-17. (Nova Série - Antropologia).

FRIKEL, P.

1963 Notas sobre a situação atual dos índios Xikrín no rio Caiteté. Revista do Museu Paulista, São Paulo, 14: 145-158.

1968 Os Xikrín. Equipamento e técnicas de subsistência. Publicações Avulsas do Museu Paraense Emílio Goeldi. Belém: Museu Paraense Emílio Goeldi, 7.

GARCIA, L.; ALMEIDA, F.O. de

2007 Técnica de manufatura: um caso de estudo observado entre sítios Tupi do Sudeste do Pará. In: Congresso da Sociedade de Arqueologia Brasileira: Arqueologia, Etnicidade e Território, 14., 2007, Florianópolis. Anais. 1 CD.

GOMES, D.M.C.

2002 Cerâmica arqueológica da Amazônia: vasilhas da coleção tapajônica MAE - USP. São Paulo: Edusp: FAPESP: Imprensa Oficial do Estado de São Paulo. 355 p.

GUAPINDAIA, V.L.C.

1993 Fontes históricas e arqueológicas sobre os Tapajó de Santarém: a coleção "Frederico Barata” do Museu Paraense Emílio Goeldi. 1993. Dissertação (Mestrado) - Universidade Federal de Pernambuco, Recife.
2000 Levantamento arqueológico em Porto Trombetas. Relatório de Pesquisas. Belém: Museu Paraense Emílio Goeldi.

2001 Relatório de Prospecção e Salvamento arqueológico nos platôs Saracá, Papagaio e Periquito e na Correia Transportadora Saracá/Aviso/Almeidas. Relatório de Pesquisa. Belém: Museu Paraense Emílio Goeldi.

KERN, D.C.; MARQUES, F.L.T.; MAURITY, C.W.; ATZINGEN, N.V.

1992 O potencial espeleoarqueológico da região do São Geraldo do Araguaia - PA. Boletim do Museu Paraense Emílio Goeldi (Antropologia), Belém, 8 (2): 157-183.

KINTIGH, K.W.

1988 The effectiveness of subsurface testing: a simulation approach. American Antiquity, 53 (4): 686-707.

KIPNIS, R.; CALDARELLI, S.B.; OLIVEIRA, W.C.

2005 Contribuição para a cronologia da colonização Amazônica e suas implicações teóricas. Revista de Arqueologia, São Paulo, 18: 81-93.

KRAKKER, J.J.; SHOTT, M.J.; WELCH, P.D.

1983 Design and evaluation of shovel-test sampling in regional archaeological survey. Journal of Field Archaeology, 10: 469-480.

LIGHTFOOT, K.G.

1986 Regional survey in the Eastern United States: the strengths and weakness of implementing subsurface testing programs. American Antiquity, 5 (13): 484 504.

LOPES, D.; SILVEIRA, M.I.; MAGALHÃES, M.

1988 Levantamento Arqueológico. In: Relatório final do Projeto estudo e preservação de recursos humanos e naturais da área do Projeto "Ferro Carajás”. Belém: Museu Paraense Emilio Goeldi, volume 1.

MACHADO, C.L.

2004 Prospecção arqueológica na área de ampliação do Aeroporto de Vitória. Relatório de Pesquisa. Vitória: RHEA Estudos e Projetos Ltda. / Infraero.

2005 Prospecção arqueológica na área dos loteamentos Perobas e Esplanada. Relatório de Pesquisa 035/05. Vitória: RHEA Estudos e Projetos Ltda./Somic.

MAGALHÃES, M.P.

1994 Relatório da excursão arqueológica realizada em Carajás em maio/junho de 
1994. Relatório de Pesquisa. Belém:

Museu Paraense Emílio Goeldi.

1995a Relatório da excursão arqueológica realizada em Carajás em agosto de 1995 (Etapa 3). Relatório de Pesquisa. Belém: Museu Paraense Emílio Goeldi.

1995b Arqueologia de Carajás. A presença préhistórica do homem na Amazônia. Rio de Janeiro: Companhia Vale do Rio Doce.

2001 Relatório da prospecção arqueológica na área da mineração Serra do Sossego. Relatório de Pesquisa. Belém: Museu Paraense Emílio Goeldi.

2005 A Physis da origem: o sentido da História na Amazônia. Belém: Museu Paraense Emílio Goeldi.

MUNSELL Color Company

1964 Munsell Soil Color Charts. Baltimore. NEVES, W.A.

1984 A evolução das estratégias de levantamento arqueológico na bacia do alto Guareí, SP. Revista de Pré-História, São Paulo, VI: 225-234.

PEREIRA, E. da S. (Coord.)

2003a Programa de arqueologia preventiva na área da mineração Serra do Sossego/PA. Relatório de Pesquisas. Belém: Museu Paraense Emílio Goeldi.

2003b Programa de arqueologia preventiva na área da mineração Serra do Sossego / PA (etapas de maio, julho e outubro 2003). Relatório de Pesquisas. Belém: Museu Paraense Emílio Goeldi.

PEREIRA, E. da S.; Machado, C.L (Coords.)

2001 Programa de arqueologia preventiva na área da mineração Serra do Sossego/PA. Projeto de Pesquisa. Belém: Museu Paraense Emílio Goeldi.

PEREIRA, E. da S.; SILVEIRA, M.I.; RODRIGUES, M.C.; L.F.; ARAÚJO COSTA, C.J.; MACHADO, C.L.

2008 A tradição Tupiguarani na Amazônia. In: Prous, A.; Lima, T.A. (Orgs.) Os ceramistas Tupiguarani. Vol. 1. Belo Horizonte, Sigma: 49-66.

PROUS, A.

1992 Arqueologia Brasileira. Brasília: Universidade de Brasília.

SALOMÃO, R.P.; SILVA, M.F.F.; ROSA, N.A.

1988 Inventário ecológico em Floresta Fluvial Tropical de Terra Firme - Serra Norte, Carajás - PA. Boletim do Museu Paraense Emílio Goeldi (Série Botânica). Belém, 4 (1): 1-46.

SILVA, M.F.F.

1989 Aspectos ecológicos da vegetação que cresce sobre canga hematitica em Carajás - PA. 1989. Tese (Doutorado) - INPA/FUA, Manaus.

1992 Análise florística da vegetação que cresce sobre canga hematitica em Carajás - Pará (Brasil). Boletim do Museu Paraense Emílio Goeldi (Série Botânica). Belém, 7 (2): 79. 108.

SILVA, M.F.F.; ROSA, N.A.

1989 Análise do extrato arbóreo da vegetação sobre jazida de cobre na Serra dos Carajás - PA. Boletim do Museu Paraense Emílio Goeldi (Série Botânica). Belém, 5 (2): 175-206.

SILVEIRA, M.I.

1994 Estudo sobre estratégias de subsistência de caçadores-coletores pré-históricos do sítio Gruta do Gavião, Carajás (Pará). Dissertação (Mestrado) - Faculdade de Filosofia, Letras e Ciências Humanas, Universidade de São Paulo, São Paulo.

SILVEIRA, M.I.; LOPES, D.F.F.

2002 O potencial arqueológico na área do Projeto Salobo, município de Marabá/PA. Relatório do Diagnóstico Arqueológico. Belém: Museu Paraense Emílio Goeldi.

SILVEIRA, M.I.; LOPES, D.F.F.; MAGALHÃES, M.P.

1985 Salvamento Arqueológico em Carajás (PA). In: Congresso da Sociedade de Arqueologia Brasileira, 3., 1985, Goiânia. Caderno de Resumos.

SILVEIRA, M.I.; MACHADO, C.L.

2002 Projeto de prospecção arqueológica na área do Projeto Salobo/PA. Projeto de Pesquisa. Belém: Museu Paraense Emílio Goeldi.

SILVEIRA, M.I.; MACHADO, C.L.; RODRIGUES, M.C.L.F.

2003a Primeiro relatório do Projeto de prospecção arqueológica na área do Projeto Salobo PA. Relatório de Pesquisa. Belém: Museu Paraense Emílio Goeldi.

2003b Segundo relatório do Projeto de prospecção arqueológica na área do Projeto Salobo PA. Relatório de Pesquisa. Belém: Museu Paraense Emílio Goeldi.

2004 Terceiro relatório do Projeto de prospecção arqueológica na área do Projeto Salobo PA. Relatório de Pesquisa. Belém: Museu Paraense Emílio Goeldi.

2005a Quarto relatório do Projeto de prospecção arqueológica na área do Projeto Salobo PA. Relatório de Pesquisa. Belém: Museu Paraense Emílio Goeldi. 
2005b Quinto relatório do Projeto de prospecção arqueológica na área do Projeto Salobo PA. Relatório de Pesquisa. Belém: Museu Paraense Emílio Goeldi.

2006 Relatório Final do Projeto de prospecção arqueológica na área do Projeto Salobo PA. Relatório de Pesquisa. Belém: Museu Paraense Emílio Goeldi.

SILVEIRA, M.I.; OLIVEIRA, E.R.; RODRIGUES, M.C.L.F.

2008 Sexto relatório do Projeto de salvamento arqueológico na área do Projeto Salobo PA (sítios Abraham, Orlando, Edinaldo e ocorrências Castanheira, Nascente e Cinzento). Relatório de Pesquisa. Belém: Museu Paraense Emílio Goeldi.

SILVEIRA, M.I.; RODRIGUES, M.C.L.F.

2005 Primeiro relatório do Projeto de salvamento arqueológico na área do Projeto Salobo - PA (sítios Barfi e Bitoca 2). Relatório de Pesquisa. Belém: Museu Paraense Emílio Goeldi.

2006a Segundo relatório do Projeto de salvamento arqueológico na área do Projeto Salobo - PA (sítios Dique BF2 e Bitoca 1). Relatório de Pesquisa. Belém: Museu Paraense Emílio Goeldi.

2006b Terceiro relatório do Projeto de salvamento arqueológico na área do Projeto Salobo - PA (sítios Pau Preto, P32, 4 Alfa e Araras). Relatório de Pesquisa. Belém: Museu Paraense Emílio Goeldi.

2007a Quarto relatório do Projeto de salvamento arqueológico na área do Projeto Salobo - PA (sítios Mirim, Marinaldo, Reginaldo, Cachoeira do Borges e Perdido do Mirim). Relatório de Pesquisa. Belém: Museu Paraense Emílio Goeldi.

2007b Quinto relatório do Projeto de salvamento arqueológico na área do Projeto Salobo - PA (sítios Alex, Sequeiro e
Marcos). Relatório de Pesquisa. Belém: Museu Paraense Emílio Goeldi.

SILVEIRA, M.I.; RODRIGUES, M.C.L.F.; OLIVEIRA, E.R.; LOSIER, L.-M.

2008 Seqüência cronológica de ocupação na área do Salobo (Pará). Revista de Arqueologia, 21 (1): 61-84.

SIMÕES, M.F.

1983 Projeto de salvamento arqueológico em Carajás. Projeto de Pesquisa. Belém: Museu Paraense Emílio Goeldi.

1986 Salvamento arqueológico. In: Almeida Jr., J.M.G. (Org.). Carajás - Desafio político, ecologia e desenvolvimento. Brasília, São Paulo: CNPq, Editora Brasiliense: 535-559.

SIMÕES, M.F.; ARAÚJO COSTA, F.

1987 Pesquisas arqueológicas no baixo rio Tocantins (Pará). Revista de Arqueologia, Belém, 4 (1): 11-27.

SIMÕES, M.F.; CORREAA, C.G.; MACHADO, A.L.

1973 Achados arqueológicos no baixo rio Fresco (Pará). O Museu Goeldi no ano do sesquicentenário - Publicações Avulsas do Museu Paraense Emílio Goeldi. Belém: Museu Paraense Emílio Goeldi, 20: 113-142.

SIMÕES, M.F.; LOPES, D.F.F.; SILVEIRA, M.I.; MAGALHÃES, M.P.

1985 Nota sobre as pesquisas arqueológicas em Carajás. American Antiquity (Current Research), 50 (1): 175.

SPURLING, B.E.

1980 Site discovery and assessment techniques for mixed-cover survey regimes. Saskatchewan Archaeology, 1: 25-56.

ZEIDLER, J.A.

1995 Archaeological survey and site discovery in the forested neotropics. In: Stahl, P.W. (Ed.) Archaeology in the lowland American tropics - Current analytical methods and recent applications. Cambridge, Cambridge University Press: 7-41. 